\title{
Biological Properties of Apple Scar Skin Viroid: Isolates, Host Range, Different Sensitivity of Apple Cultivars, Elimination, and Natural Transmission
}

\author{
J. C. Desvignes, N. Grasseau, R. Boyé, and D. Cornaggia, CTIFL, Lanxade Center, BP 21, F-24130 La Force, \\ France; and F. Aparicio, F. Di Serio, and R. Flores, Instituto de Biologia Molecular y Celular de Plantas (UPV- \\ CSIC), Camino de Vera, 14, E-46022 Valencia, Spain
}

\begin{abstract}
Desvignes, J. C., Grasseau, N., Boyé, R., Cornaggia, D., Aparicio, F., Di Serio, F., and Flores, R. 1999. Biological properties of apple scar skin viroid: Isolates, host range, different sensitivity of apple cultivars, elimination, and natural transmission. Plant Dis. 83:768-772.

Studies conducted over the last 10 years have revealed that the disease caused by the apple scar skin viroid (ASSVd) is extremely rare in Europe. ASSVd was detected by molecular hybridization and indexing in field plots on the apple indicators Starkrimson and Indo, which showed symptoms of dapple apple disease within 2 years, and rough scarred skin within 3 years, respectively. Results from both approaches were in agreement. In an attempt to improve the biological detection of ASSVd, the Japanese PK13 isolate was inoculated to 4 Prunus, 13 Malus, 17 Pyrus, and 17 other pomaceous species. All the species tested of the Malus, Pyrus, Sorbus, Chaenomeles, Cydonia, and Pyronia genera were susceptible to ASSVd based upon back indexing and hybridization, but none developed leaf or bark symptoms during a 2-year period. The viroid was not detected in the tested members of genera Amelanchier, Aronia, Cotoneaster, Crataegus, Prunus, and Pyracantha. Symptoms on fruit of 42 commercial apple cultivars experimentally inoculated with ASSVd fell into five groups ranging from inconspicuous spots to severely scarred skin and cracking. ASSVd was eliminated from most of the infected apple plants when they were subjected to a dormant stage followed by thermotherapy and shoot tip grafting. Analysis of more than 400 apple seedlings, originated from Starkrimson and Indo fruits with typical ASSVd symptoms, showed that there is little or no seed transmission of this viroid. However, ASSVd was transmitted at a low rate under field conditions to adjacent trees.
\end{abstract}

Additional keywords: detection, Malus viroid

The apple scar skin disease was first reported 60 years ago in China (Manchuria) with the name "Manshu-sabika-byo" (19). Twenty years later, two apple disorders were described simultaneously in the United States: the apple scar skin disease on cv. Red Delicious in Missouri (18), and the dapple apple disease on cv. Cortland in New Hampshire (26). Again 20 years later, similar fruit symptoms were seen occasionally in Italy (9) and in the United Kingdom (3). The two diseases were attributed to the same infectious agent (28), which is quite widespread on apple and Asian pear (Nashi) in some China provinces (27). This infectious agent is now known to be a viroid, called apple scar skin viroid (ASSVd), whose sequence of 330 nucleotides was first determined in Japan in 1987 (12). Recent evidence, however, suggests that the symptoms observed in Italy (9) were probably induced by another viroid of 306 nucleotides (6), called apple

Corresponding author: J. C. Desvignes

E-mail: s-lanxade@ctifl.fr

Accepted for publication 7 May 1999.

Publication no. D-1999-0601-01R

(C) 1999 The American Phytopathological Society dimple fruit viroid (ADFVd), belonging also to the genus Apscaviroid, whose type member is ASSVd (8).

In 1987, in collaboration with Lemoine (INRA-Angers, France) (16), we imported to our laboratory in CTIFL-Lanxade, France, an ASSVd-infected apple source (PK13) from Japan, to determine the hosts and the different symptoms induced by this viroid under the climatic conditions of Aquitaine (France). Here we report results from our last 10 years of studies on ASSVd detection by indexing and molecular hybridization, together with the sequence variability of some isolates, the susceptibility of some pomaceous genera and species, and the damage induced in certain apple varieties. We have also examined ASSVd thermostability and its transmissibility under different conditions.

\section{MATERIALS AND METHODS}

ASSVd isolates. The PK13 isolate was indexed on Pyronia veitchii, the apple cultivars Spy 227, Virginia Crab, Indo, Starkrimson, Golden Delicious, and Lord Lambourne, as well as on Prunus avium cv. F12-1, to detect the possible presence of apple chlorotic leaf spot trichovirus (ACLSV), apple stem pitting foveavirus (ASPV), apple stem grooving capillovirus (ASGV), apple mosaic ilarvirus (ApMV), apple green crinkle virus (AGCV), and the phytoplasmas inducing apple rubbery wood and apple proliferation (4). In addition to PK13, five additional Japanese sources infected by ASSVd (P112, X4530, $\mathrm{X} 4533$, X4573, and X4843) were introduced in Lanxade in 1990, grafted on seedlings in the greenhouse, and indexed on three in vitro-propagated indicators (5).

Cloning and sequencing of ASSVd. Purified viroid circular forms from PK13 and X4533 isolates were obtained as described previously $(7,20)$. First-strand cDNAs were synthesized with avian myeloblastosis virus reverse transcriptase (RT) (Boehringer-Mannheim GmbH, Germany) and a primer complementary to positions 70 to 89 of the ASSVd reference sequence (12). Second-strand cDNAs were produced by polymerase chain reaction (PCR) (23) with the primer used in the RT reaction and a second adjacent primer homologous to positions 90 to 110 of the ASSVd reference sequence and cloned $P f u$ DNA polymerase using the buffer suggested by the producer (Stratagene, La Jolla, CA) for maximal fidelity. The PCR cycling profile (30 cycles) was $94^{\circ} \mathrm{C}$ for $40 \mathrm{~s}, 50^{\circ} \mathrm{C}$ for 1 min, and $72^{\circ} \mathrm{C}$ for $2 \mathrm{~min}$, with a final extension step at $72^{\circ} \mathrm{C}$ for $10 \mathrm{~min}$. PCRamplified products of the expected full length were cloned in the EcoRV site of pBluescript II KS+, and the inserts were sequenced with chain terminating inhibitors (24).

Host range. To explore the susceptibility of different Prunus species to ASSVd, the PK13 isolate was inoculated by double budding in September 1990 onto nursery plants of $P$. armeniaca cv. Priana, $P$. avium cvs. Bing and Sam, $P$. insititia cv. Krikon, and $P$. persica cvs. GF 305 and Springtime (five plants of each accession). Back inoculations were performed in the summer of 1991 on cv. Starkrimson, and the corresponding fruits were observed in 1993 and 1994.

In order to search for a faster ASSVd indicator, 17 species of 9 genera close to Malus (Amelanchier, Aronia, Chaenomeles, Cotoneaster, Crataegus, Cydonia, Pyracantha, Pyronia and Sorbus) were inoculated in 1994 with the PK13 isolate and kept in the greenhouse. The PK13 isolate was also inoculated on 17 Pyrus and 13 Malus species. Some of these plants were seedlings, and some were propagated by grafting on apple or pear seedlings. 
After a vegetative period in the greenhouse to watch for the appearance of visible symptoms, the plants were transferred to a nursery to record any leaf, bark, or growth alteration for the next 2 to 3 years. Leaves and shoots were taken from 1995 to 1997 to analyze ASSVd presence by molecular hybridization. Some back inoculations on Starkrimson were also made in the 1995 summer to compare ASSVd detection by the molecular and biological procedures.

Different sensitivity of commercial apple cultivars to ASSVd. Two series of 20 and 22 virus-free apple cultivars were budded on Pajam (M9 type) rootstocks in September 1993 and 1994, respectively, and inoculated simultaneously with chips of an apple tree infected with the PK13 isolate of ASSVd. Fruits were observed in the field from 1995 to 1998 . Three trees were examined for each cultivar.

Molecular hybridization. Extraction of nucleic acids from fruits, bark, or leaves (2 months or older) and dot blot hybridization, using radioactive or digoxigeninlabeled full-length ASSVd complementary RNA probes, were carried out following two protocols reported previously $(2,10)$.

In some experiments, detection of ASSVd in apple fruits was performed comparatively by tissue extraction and tissue blotting (15) every other week from April to August 1997. Small cylinders were cut off in duplicate from the mesocarp of 24 ASSVd-inoculated cultivars, 9 of which had no fruit symptoms, 10 with dapple apple symptoms, and 5 with severe scar skin symptoms. One sample was used to prepare the extract, and the other was applied directly to the nylon membrane (N+ Boehringer-Mannheim) by pressing the freshly cut tissue surface.

Thermotherapy and shoot tip grafting. To test the thermostability of ASSVd in apple trees, as well as to obtain pure viroid sources by elimination of the accompanying viruses, plants of clones PK13, P112, and X4843 were treated at 36 to $37^{\circ} \mathrm{C}$ for 41 days in October 1993 , and others of clone X4573 for 99 days also at the end of this year. On the other hand, after being dormant for 3 months at 4 to $5^{\circ} \mathrm{C}$ in a cool chamber, plants of clones PK13, X4530, X4533, and X4843 were treated at 36 to $37^{\circ} \mathrm{C}$ for 48 days in early 1994. At the end of the treatments, apical tips ( 2 to $4 \mathrm{~mm}$ ) were collected and grafted onto young apple seedlings or onto in vitro-propagated Virginia Crab. The resulting plants were examined by indexing on specific indicators to detect the different viruses, and by hybridization with an ASSVd-specific probe. Some clones were also indexed on Starkrimson to verify the hybridization results.

Natural transmission. Seventeen Starkrimson or Indo plants, grafted on Pajam (M9 type) and inoculated in 1990 by double-budding with the ASSVd isolate PK13, were transferred at the beginning of 1992 to a separated experimental orchard, with $2 \times 3 \mathrm{~m}$ tree spacing, where they were surrounded by 90 noninoculated plants of the same varieties whose fruits were then observed for 5 years to detect any ASSVd transmission under field conditions. Additionally, from 1993 onward, we also regularly observed the indicator trees Starkrimson and Indo grown in the indexing plots to detect any eventual contamination of the healthy controls or tests.

To evaluate seed transmissibility of ASSVd, symptomatic fruits from Starkrimson and Indo trees inoculated with isolate PK13 were harvested in 1992. Nearly 280 Indo and 160 Starkrimson seedlings were grown in the greenhouse in 1993, and 266 and 140 of them, respectively, were indexed in 1994 on the indicator Starkrimson budded on Pajam rootstock, and the fruits of the corresponding 406 trees were observed in 1995 and 1996.

\section{RESULTS AND DISCUSSION}

Detection of ASSVd by biological indexing. No reaction was observed on leaf, bark, and wood of the different indicators inoculated with the ASSVd isolate PK13, except on Indo and Starkrimson fruits. Therefore, this isolate was assumed to be a pure source of ASSVd and was used as a positive control in all subsequent assays. The dappled discolorations induced by the PK13 isolate on Starkrimson were observed 2 years after inoculation and were similar to those described on Cortland (16). They appeared in July, when the apple skin turns red, becoming progressively accentuated until September. Starkrimson fruits also exhibited small rough mottles, sometimes starred around the eye cavity. On Indo, the PK13 isolate induced rough plates or mottles and occasionally cracks, often concentrated around the eye cavity. This russeting or scarred skin started in May (3 years after double budding) and appeared like that described on Red Delicious (1), but was generally milder.

Biological indexing disclosed that the other five ASSVd isolates were also infected by one or more viruses: P112,
X4530, and X4533 by ACLSV, ASPV, and ASGV; X4573 by ASPV and ASGV; and X4843 by ASGV. With these isolates, and the virus-free subisolates obtained from them by thermotherapy, we observed the same typical symptoms on the two ASSVd indicators: dapple apple on Starkrimson and scar skin on Indo. Only the X4533 isolate appeared more severe on Indo. Infection by ACLSV, ASPV, and ASGV did not alter the indicator reactions.

Detection of ASSVd by molecular hybridization. Extracts from apple tissues (fruits, buds, bark, and leaves) 2 months or older from ASSVd-infected plants grown in the greenhouse or in the field gave intense hybridization signals with both probes, radioactive or digoxigenin-labeled, indicating relatively high viroid titers. However, the intensity of the signals generated by pear and other species were generally weaker or lacking in precision. The CF11-based method (10), which produced cleaner and more concentrated extracts, combined with the digoxigenin-labeled probe, permitted us to perform about 50 tests per week per person in Lanxade in 1997, effectively 700 tests between April and July. Successful detection of ASSVd in apple extracts by dot blot hybridization using a radioactive probe has already been reported (25).

The assay reliability was poorer when sections of leaf or shoot tissue were directly blotted onto the membrane: clear hybridization signals were detected only in 70 to $75 \%$ of the apple samples known to be ASSVd-infected by biological indexing. Apples collected from April to July produced only a white halo, probably due to a diffusible substance that prevented binding of RNA to the membrane, whereas the corresponding extracts gave intense hybridization signals. However, nucleic acid extractions and tissue blotting of fruit sections taken from August onward provided comparable good results. The signal intensity of the tolerant or susceptible fruits was similar. In previous experiments to detect ASSVd in pear by molecular hybridization, tissue imprints often turned brown in the membranes that produced corresponding clear areas on the detection film (15).

Molecular characterization of two ASSVd isolates. To confirm the ASSVd nature of the isolates under study and to obtain an idea of their sequence variability, several PK13 and X4533 cDNA clones were synthesized by reverse transcriptionpolymerase chain reaction (RT-PCR) using ASSVd-specific primers derived from the

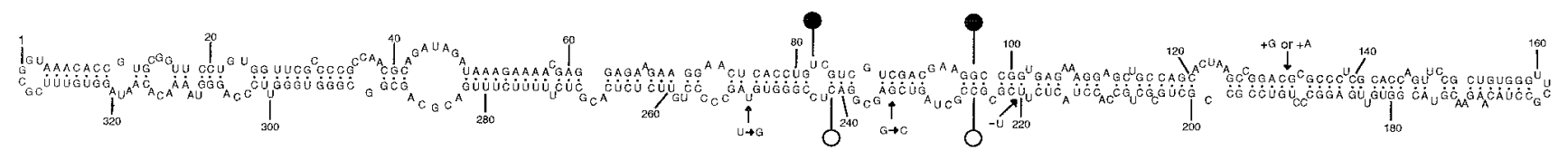

Fig. 1. Changes detected in clones of the PK13 and X4533 isolates of apple scar skin viroid with respect to the reference sequence of this viroid (12). The upper and lower strands of the central conserved region are delimited by black and white circles, respectively. 
reference sequence of this viroid (12). Two of the four PK13 clones analyzed had a sequence identical to the reference. The other two PK13 clones had alterations: an
A insertion after position 132 in one, and a $\mathrm{G}$ insertion after position 132 together with a $\mathrm{G} \rightarrow \mathrm{C}$ substitution in position 233 in the other (Fig. 1).

Table 1. Susceptibility of pomaceous species to apple scar skin viroid (PK13 isolate)

\begin{tabular}{lccc}
\hline Species & Propagation $^{\mathbf{a}}$ & Hybridization $^{\mathbf{b}}$ & Indexing $^{\mathbf{c}}$ \\
\hline Amelanchier canadensis & $\mathrm{Se}$ & - & $\mathrm{NT}$ \\
Amelanchier lamarckii & $\mathrm{Ga}^{\mathrm{d}}$ &,-- & $\mathrm{NT}$ \\
Amelanchier ovalis & $\mathrm{Se}$ & - & $\mathrm{NT}$ \\
Aronia melanocarpa & $\mathrm{Se}$ & - & - \\
Chaenomeles japonica & $\mathrm{Se}$ & + & + \\
Cotoneaster franchetii & $\mathrm{Se}$ & - & - \\
Crataegus coccinoides & $\mathrm{Se}$ & - & - \\
Crataegus marshalii & $\mathrm{Ga}$ & - & - \\
Crataegus monogyna & $\mathrm{Ga}$ & - & - \\
Crataegus viridis & $\mathrm{Se}$ & + & - \\
Cydonia oblonga & $\mathrm{Se}$ & - & + \\
Pyracantha coccinea & $\mathrm{Se}$ &,++ & - \\
Sorbus aucuparia & $\mathrm{Ga}$ & + &,+ \\
Sorbus domestica & $\mathrm{Se}$ &,++ & $\mathrm{NT}$ \\
Sorbus mougeotii & $\mathrm{Ga}$ and Se & + &,++ \\
Sorbus prattii & $\mathrm{Se}$ & + & + \\
$\times$ Pyronia veitchii & $\mathrm{Gp}$ & + \\
\hline
\end{tabular}

a Plants were propagated by seed (Se), or by grafting on apple (Ga) or pear (Gp) seedlings.

${ }^{\mathrm{b}}+$, visible signal; - , no signal.

c + , fruit symptoms on Starkrimson; -, no symptoms; NT, not tested.

d Buds from two origins.

Table 2. Susceptibility of Pyrus species to apple scar skin viroid (PK13 isolate)

\begin{tabular}{lccc}
\hline Species & Propagation $^{\mathbf{a}}$ & Hybridization $^{\mathbf{b}}$ & Indexing $^{\mathbf{c}}$ \\
\hline$P$. amygdaliformis & $\mathrm{Gp}^{\mathrm{d}}$ &,++ &,++ \\
$P$. amygdaliformis & $\mathrm{Se}$ & + & + \\
$P$. betulifolia & $\mathrm{Gp}$ & + & + \\
$P$. calleryana & $\mathrm{Gp}^{\mathrm{d}}$ &,++ &,++ \\
$P$. canescens & $\mathrm{Gp}$ and Se &,++ &,++ \\
$P$. communis & $\mathrm{Gp}$ & + & + \\
$P$. communis & $\mathrm{Gp}$ & + & + \\
$P$. nivalis & $\mathrm{Gp}$ & + & + \\
$P$. persica & $\mathrm{Gp}$ & + & + \\
$P$. pyrifolia & $\mathrm{Gp}$ & $\mathrm{NT}$ & + \\
$P$. salicifolia & $\mathrm{Gp} \mathrm{and} \mathrm{Se}$ &,++ &,++ \\
$P$. ussuriensis & $\mathrm{Gp}$ & + & + \\
$P . \times$ michauxii & $\mathrm{Gp}$ & + & + \\
$P y$ rus $\times$ Malus hybrid & $\mathrm{Gp}$ & + & + \\
$\times$ Sorbopyrus auricularis & $\mathrm{Gp}$ & + & + \\
$\times$ Sorbopyrus auriculatus & $\mathrm{Gp}$ & + & - \\
$\times$ Sorbaronia alpina & $\mathrm{Gp}$ & + & + \\
\hline
\end{tabular}

a Plants were propagated by seed (Se), or by grafting (Gp) on pear seedlings.

${ }^{\mathrm{b}}+$, visible signal; - , no signal; NT, not tested.

c + , fruit symptoms on Starkrimson; -, no symptoms; NT, not tested.

d Buds from two origins.

Table 3. Susceptibility of Malus species to apple scar skin viroid (PK13 isolate)

\begin{tabular}{lccc}
\hline Species & Propagation $^{\mathbf{a}}$ & Hybridization $^{\mathbf{b}}$ & Indexing $^{\mathbf{c}}$ \\
\hline M. baccata f. gracilis & $\mathrm{Ga}$ & + & + \\
$M$. baccata & $\mathrm{Se}$ & + & + \\
$M$. floribunda & $\mathrm{Se}$ & + & + \\
$M$. hupehensis & $\mathrm{Se}$ & + & + \\
$M$. ioensis & $\mathrm{Se}$ & + & + \\
$M$. micromalus & $\mathrm{Ga}$ & + & + \\
$M$. platycarpa & $\mathrm{Se}$ & + & + \\
$M$. pruni & $\mathrm{Ga}$ & + & + \\
$M$. pumila & $\mathrm{Ga}$ and Se &,++ & + \\
$M$. purpurea & $\mathrm{Se}$ & + & + \\
$M$. toringo & $\mathrm{Se}$ &,++ &,++ \\
$M . \times$ robusta & $\mathrm{Ga}$ and Se &,++ &,++ \\
$M$ yunnanensis & Ga and Se & +
\end{tabular}

a Plants were propagated by seed (Se), or by grafting (Ga) on apple seedlings.

$\mathrm{b}+$, visible signal.

${ }^{\mathrm{c}}+$, fruit symptoms on Starkrimson.

The two sequenced clones of the X4533 severe isolate also presented changes relative to the reference sequence: deletion of $\mathrm{U} 220$ and $\mathrm{U} 250 \rightarrow \mathrm{G}$ in one of the clones, and a $\mathrm{G}$ insertion after position 132, deletion of $\mathrm{U} 220$ and $\mathrm{U} 250 \rightarrow \mathrm{G}$ in the second one (Fig. 1). Whereas some of the sequence alterations observed here ( $\mathrm{G}$ insertion after position 132, deletion of U220, and substitution $\mathrm{U} 250 \rightarrow \mathrm{G}$ ) have been reported in other ASSVd isolates from apple and pear $(22,29,30)$, it is interesting to note that the $\mathrm{G} 234 \rightarrow \mathrm{C}$ substitution is unique because this position is part of the lower strand of the central conserved region, which remains unaltered in members of the ASSVd viroid genus (8). However, despite having used a thermostable DNA polymerase with proofreading activity, we cannot exclude the possibility that this latter substitution may be a cloning artifact. One or more of the differential changes observed between the PK13 and the X4533 isolates might explain the more severe symptoms induced by the latter.

Susceptibility of different Prunus and pomaceous genera to infection by ASSVd. All back inoculations performed on Starkrimson with the ASSVd-inoculated Prunus were negative. Most likely, this is not the result of a Malus/Prunus incompatibility, because ACLSV and ApMV are easily transmitted from apple to Prunus by graft and ASSVd needs a shorter contact time (2 to 3 days) than viruses to move into the receptor plant (data not shown). Neither symptoms on leaves and bark nor growth anomalies appeared on seedlings (10 to 15 plants per test) or on the graft-propagated plants (five repetitions per test) of the 17 pomaceous species over a period of 2 years. Several of the pomaceous genera were not infected by ASSVd (Table 1). The viroid was detected only in Sorbus, Chaenomeles, Cydonia, and Pyronia (Table 1), but none expressed any detectable symptoms.

All of the species of Pyrus and Malus genera were susceptible (Tables 2 and 3), but none developed symptoms. The negative results from back indexing of Sorbaronia alpina and Pyrus ussuriensis need confirmation. Therefore, none of these species can be used as an indicator to replace Malus pumila, which requires a long indexing period. It has been reported, however, that indexing time can be considerably reduced by using apple cultivars Stark's Earliest and Sugar Crab maintained in growth chambers under defined conditions (25) and observing the epinasty that ASSVd induces.

Symptoms induced by ASSVd on commercial apple cultivars. The sensitivity of the main apple cultivars grown in France was assessed either on one clone in the case of homogeneous varieties such as Granny Smith, or on three to six cultivars in nonhomogeneous varieties, such as Red Delicious with mutants Ace, Early Red 
One, Oregon Spur, Red Chief, Starkrimson, and Top Red Delicious. The varieties were classified into five groups according to their reaction to ASSVd (Table 4). With the tolerant cultivars (group A), only inconspicuous spots or discolorations appeared on a few fruits. In slightly sensitive or susceptible cultivars (groups B and C), the epidermis was spotted by dapples of mild to moderate intensity, usually only on a fraction of the fruits (17). With the more susceptible cultivars (group D), nearly all the fruits were damaged by discolorations or dapples and by russeting or rough star at the eye cavity. Finally, the very susceptible cultivars (group E) displayed severe symptoms of necrosis, cracks, and rough skin before maturity (Fig. 2). Commer-

Table 4. Sensitivity of 42 commercial apple cultivars to apple scar skin viroid (PK13 isolate) according to symptoms observed from 1995 to 1998 in Lanxade (France)

\begin{tabular}{|c|c|c|}
\hline Sensitivity group & Fruits symptoms & Varieties \\
\hline $\mathrm{A}-$ tolerant & Inconspicuous spots & $\begin{array}{l}\text { Golden Delicious (3) }{ }^{\mathrm{a}} \text {, Smoothee, } \\
\text { Jonagold, Pink Lady, Reine des } \\
\text { Reinettes, Belrène, Reinette Grise du } \\
\text { Canada, Granny Smith, Baujade }\end{array}$ \\
\hline B - slightly sensitive & Mild dapple apple & $\begin{array}{l}\text { Fuji and mutants (6), Gala and mutants } \\
\text { (4), Akane, Ambassy, Delbarestivale, } \\
\text { Redwinter, Spurkoop }\end{array}$ \\
\hline $\mathrm{C}$ - susceptible & $\begin{array}{l}\text { Strong discolorations (clear } \\
\text { dapple apple) }\end{array}$ & $\begin{array}{l}\text { Elstar and mutants (3), Delbard Jubilé, } \\
\text { Festival, Querina, Sunrise }\end{array}$ \\
\hline D - more susceptible & $\begin{array}{l}\text { Necrosis and discolorations } \\
\text { (scar skin and dapple apple) }\end{array}$ & $\begin{array}{l}\text { Red Delicious and mutants (5) of which } \\
\text { Ace, Early Red One, Red Chief and } \\
\text { Starkrimson, Charden (star at } \\
\text { depression of eye) }\end{array}$ \\
\hline E - very sensitive & $\begin{array}{l}\text { Necrosis, cracks on all fruits } \\
\text { (scar skin, with or without } \\
\text { dapple apple) }\end{array}$ & $\begin{array}{l}\text { Braeburn, Hillwell, and mutants (4), } \\
\text { Belchard, Indo (Japanese cv. indicator) }\end{array}$ \\
\hline
\end{tabular}

a Number of cultivars tested in the case of nonhomogeneous varieties is indicated within parentheses.

cially, apples from groups $\mathrm{B}$ and $\mathrm{C}$ are downgraded, and those of groups $\mathrm{D}$ and $\mathrm{E}$ are generally unmarketable.

Although these results indicate that most apple cultivars grown in France are sensitive to ASSVd, we have never observed ASSVd symptoms in commercial orchards. Molecular hybridization and biological indexing have confirmed that this viroid is absent or extremely infrequent in France.

Elimination of ASSVd. For the first treatments of 41 and 99 days at 36 to $37^{\circ} \mathrm{C}$, performed at the end of the vegetative period, 30 and 8 tips, respectively, were taken and tested: 36 were found free of viruses, but only one tip each of PK13 and X4573 were recovered as ASSVd-free. For the second treatment of 48 days performed on young shoots in January 1994 after a dormant stage of 3 months, 38 virus- and ASSVd-free tips were recovered, whereas 5 others were still infected only by ASSVd. This second treatment was clearly superior and produced a majority of ASSVd-free plants (about 90\%), similar to previous experiments aimed at eliminating this viroid from infected pears by in vitro thermotherapy $\left(30\right.$ to $\left.38^{\circ} \mathrm{C}\right)$ or cryotherapy $\left(4^{\circ} \mathrm{C}\right)$ followed by apical meristem culture (21).

On the other hand, because common viruses were eliminated in nearly all the plants resulting from thermotherapy, we
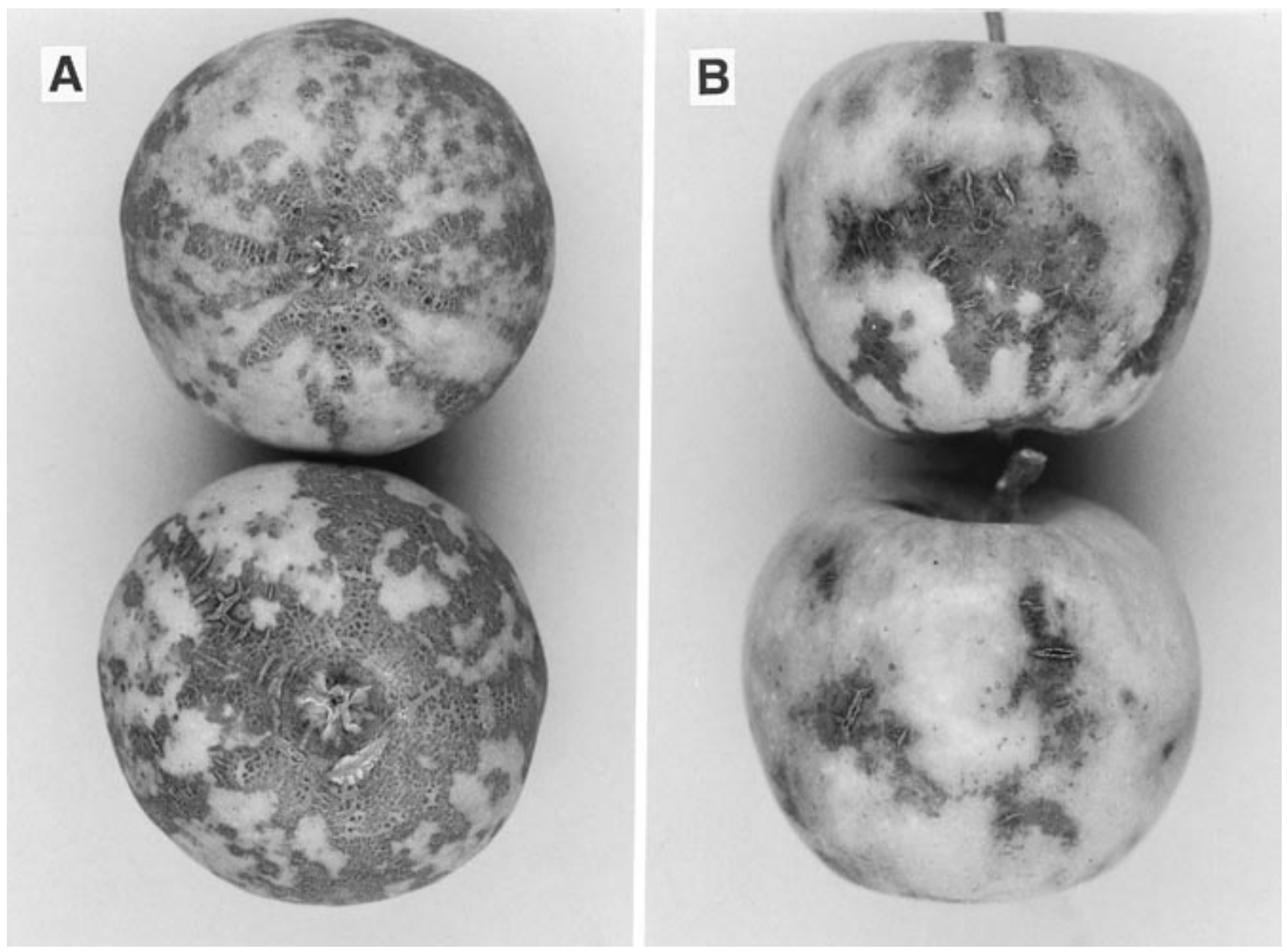

Fig. 2. Fruits of apple cultivars Belchard (A) and Braeburn (B) showing symptoms induced by isolate PK13 of apple scar skin viroid. 
could in this way obtain pure subisolates from all ASSVd isolates.

Transmission in the field and by seed. In the experimental orchard of 90 noninoculated apple trees surrounding 17 ASSVd-infected ones, which started showing symptoms in 1993, one and two initially healthy plants adjacent to inoculated ones produced symptomatic fruits on some branches in 1995 and 1996, respectively, four and five seasons after the planting. In 1997, these three trees had symptomatic fruits on all branches. They may have been infected by root grafting, a frequent situation that permits the horizontal transmission of viruses in apple orchards over a period of 4 to 5 years (J. C. Desvignes, unpublished observations). On the other hand, in the indexing plots where the plants remained only 3 to 4 years under conditions promoting a weaker growth, no infection of the healthy plants occurred.

The 406 seedlings that originated from ASSVd-infected Starkrimson and Indo fruits did not induce any reaction when bioassayed on the Starkrimson indicator, showing they were ASSVd-free. Therefore, although ASSVd has been detected in whole seeds from infected pome fruits, particularly in the seed coats and subcoats and in lesser amounts in the embryos and cotyledons (11), our observations indicate that this viroid is not seed-transmitted or is transmitted at a very low rate. This is consistent with previous results showing that ASSVd is not seedtransmitted in oriental pear (14) and with others recently published demonstrating the lack of ASSVd transmission through apple seed (13).

\section{ACKNOWLEDGMENTS}

We thank A. Ahuir for excellent technical assistance and M. de la Peña for helping to prepare Figure 1. This work was partially supported by contract AIR3CT93-1567 from the European Commission (to J. C. Desvignes and R. Flores) and by grant PB95-0139 from the Dirección General de Investigación Cíentifica y Técnica of Spain (to R. Flores).

\section{LITERATURE CITED}

1. Agrios, G. N. 1989. Apple scar skin. Pages 63-68 in: Virus and Viruslike Diseases of Pome Fruits and Simulating Noninfectious
Disorders. P. R. Fridlund, ed. Washington State University, Pullman.

2. Ambrós, S., Desvignes, J. C., Llácer, G., and Flores, R. 1995. Peach latent mosaic and pear blister canker viroids: Detection by molecular hybridization and relationships with specific maladies affecting peach and pear trees. Acta Hortic. 386:515-521.

3. Campbell, A. I., and Sparks, T. R. 1976. Experiments with dapple apple virus. Acta Hortic. 67:261-264.

4. Desvignes, J. C. 1990. Pages 89-109 in: Maladies à virus des arbres fruitiers. Ctifl, Paris.

5. Desvignes, J. C., Boyé, R., Cornaggia, D., and Grasseau, N. 1992. Quick detection of the principal apple and pear virus diseases. Acta Hortic. 309:377-384.

6. Di Serio, F., Aparicio, F., Alioto, D., Ragozzino, A., and Flores, R. 1996. Identification and molecular properties of a $306 \mathrm{nu}-$ cleotide viroid associated with apple dimple fruit disease. J. Gen. Virol. 77:2833-2837.

7. Flores, R., Hernández, C., Llácer, G., and Desvignes, J. C. 1991. Identification of a new viroid as the putative causal agent of pear blister canker disease. J. Gen. Virol. 72:1199-1204.

8. Flores, R., Randles, J. W., Bar-Joseph, M., and Diener, T. O. 1998. A proposed scheme for viroid classification and nomenclature. Arch. Virol. 143:623-629.

9. Giunchedi, L. 1976. Transmission experiments on the virus disease dapple apple. Acta Hortic. 67:255-260.

10. Grasseau, N., Macquaire, G., Boyé, R., Cornaggia, D., and Desvignes, J. C. Peach red marbling and peach sooty ringspot, two new virus-like degenerative diseases of Prunus. Plant Pathol. In press.

11. Hadidi, A., Hansen, A. J., Parish, C. L., and Yang, X. 1991. Scar skin and dapple apple viroids are seed-borne and persistent in infected apple trees. Res. Virol. 142:289-296.

12. Hashimoto, J., and Koganezawa, H. 1987. Nucleotide sequence and secondary structure of apple scar skin viroid. Nucleic Acids Res. 15:7045-7052.

13. Howell, W. E., Skrzeczkowski, L. J., Mink, G. I., Nunez, A., and Wessels, T. 1998. Nontransmission of apple scar skin viroid and peach latent mosaic viroid through seed. Acta Hortic. 472:635-639.

14. Hurtt, S. S., and Podleckis, E. V. 1995. Apple scar skin viroid is not seed transmitted or transmitted at a low rate in oriental pear. Acta Hortic. 386:544-550.

15. Hurtt, S. S., Podleckis, E. V., and Howell, W. E. 1996. Integrated molecular and biological assays for rapid detection of apple scar skin viroid in pear. Plant Dis. 80:458-462.

16. Lemoine, J. 1990. Etat sanitaire des pommiers et poiriers asiatiques. Phytoma 420:25-26.

17. McCrum, R. C. 1989. Dapple apple. Pages
51-54 in: Virus and Viruslike Diseases of Pome Fruits and Simulating Noninfectious Disorders. P. R. Fridlund, ed. Washington State University, Pullman.

18. Millikan, D. F., and Martin, W. R., Jr. 1956. An unusual fruit symptom in apple. Plant Dis. Rep. 40:229-230.

19. Ohtsuka, Y. 1938. On Manshu-sabika-byo of apple, graft transmission and symptom variation in cultivars. J. Jpn. Soc. Hortic. Sci. 9:282-286 (in Japanese).

20. Pallás, V., Navarro, A., and Flores, R. 1987. Isolation of a viroid-like RNA from hop different from hop stunt viroid. J. Gen. Virol. 68:3201-3205.

21. Postman, J. D., and Hadidi, A. 1995. Elimination of apple scar skin viroid from pears by in vitro thermotherapy and apical meristem culture. Acta Hortic. 386:536-543.

22. Puchta, H., Luckinger, R., Yang, X., Hadidi, A., and Sänger, H. L. 1990. Nucleotide sequence and secondary structure of apple scar skin viroid (ASSVd) from China. Plant Mol. Biol. 14:1065-1067.

23. Saiki, R. K., Gelfand, D. H., Stoffel, S., Scharf, S. J., Higuchi, R., Horn, G. T., Mullis, K. B., and Erlich, H. A. 1988. Primer-directed enzymatic amplification of DNA with a thermostable DNA polymerase. Science 239:487491.

24. Sanger, F., Nicklen, S., and Coulson, A. R. 1977. DNA sequencing with chain terminating inhibitors. Proc. Natl. Acad. Sci. U.S. 74:5463-5467.

25. Skrzeczkowski, L. J., Howell, W. E., and Mink, G. I. 1993. Correlation between leaf epinasty symptoms on two apple cultivars and results of cRNA hybridization for detection of apple scar skin viroid. Plant Dis. 77:919-921.

26. Smith, W. W., Barrat, J. G., and Rich, A. E. 1956. Dapple apple, an unusual fruit symptom of apples in New Hampshire. Plant Dis. Rep. 40:765-766.

27. Tien, P., and Chen, W. 1988. Studies on apple scar skin viroid. Pages 18-26 in: Yamanashi Viroid Disease Workshop of the International Viroid Working Group.

28. Yamaguchi, A., and Yanase, H. 1976. Possible relationship between the causal agent of dapple apple and scar skin. Acta Hortic. 67:249254.

29. Yang, X., Hadidi, A., and Hammond, R. W. 1992. Nucleotide sequence of apple scar skin viroid reverse transcribed in host extracts and amplified by the polymerase chain reaction. Acta Hortic. 309:305-309.

30. Zhu, S. F., Hadidi, A., Hammond, R. W., Yang, X., and Hansen, A. J. 1995. Nucleotide sequence and secondary structure of pome fruit viroids from dapple apple diseased apples, pear rusty skin diseased pears and apple scar skin symptomless pears. Acta Hortic 386:554-559. 